\title{
EXPERIMENTAL EVALUATION OF A CI ENGINE WITH BLENDS OF DIESEL AND PLASTIC PYROLYSIS OIL
}

\author{
P.S.Burli ${ }^{1}$

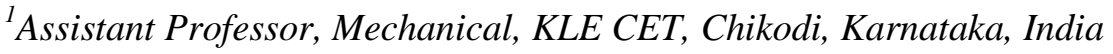

\begin{abstract}
Plastic waste disposal is a severe problem which leads to a great environmental pollution. Conventional fuels like Petrol and diesel are exhaustible hence alternative fuels find permanent solution in this regard. In this paper main focus has been made on waste plastic oil to use in the IC engine. The oil is blended with diesel in the ratio10,15,20 \&30\% \& then tested in 4-S single cylinder engine (VCR Engine.).Result analysis of the blended oil experiment shows suitability for the internal combustion engine. Performance character of the blend oil B2O shows better as compare to other blends also B2O can be used as alternative fuel oil to diesel.
\end{abstract}

Keywords: Engine, Engine Performance, Alternative Fuel, Pyrolysis, Engine Emission.

\section{INTRODUCTION}

In today's life plastics are being used every where i.e in packing goods, manufacturing home appliances, machine components etc. as they are cheap, light weight and durable. Plastics are made of petroleum and its derivatives. The plastics are biodegradable hence its waste is increasing day by day in our surrounds. Plastics waste if disposed continuously leads to severe environmental pollution. Plastics cannot be buried or land filled to degrade. Burning of plastic also produces toxic gases hence that also not advisable. The recycling of plastic of course is difficult as different types of polymers are used to manufacture according the requirement but is now essential. Many plastics can be recycled. The PET bottles are recycled to manufacture products like bean bags, sleeping bags, tennis balls, combs ets. HDPE plastic can be reused for manufacturing .In our present research work focus is made to produce oil from waste plastics.

One of the important recycling processes of plastic waste is Pyrolysis process. pyrolysis is thermo chemical decomposition of organic material in presence of oxygen. The present work is on conversion of waste plastic oil in to usable oil for the running of IC engine. In this paper, preparation of blends of diesel oil with plastic pyrolisis oil at different proportion has been presented. The waste plastic oil thus produced is checked for feasibility as an alternate fuel oil for IC engine. Performance test is conducted on computerized single cinder $4-\mathrm{S}$ diesel engine.

\section{WASTE PLASTIC PYROLYSIS OIL}

One of the most effective method of disposing of plastic is pyrolysis. It is the process of converting waste plastic to re usable fuel oil. The Pyrolysis process is taken place in the reactor. Pyrolysis is the process thermal decomposition in the absence of air. Pyrolysis involves breaking of large molecule in to smaller ones. In pyroliysis plastic will not be burnt instead broken down to usable fuel oil HC gas and carbon black. In Plastic pyrolysis plastic waste is subjected to high temperature i.e more than 500 degree centigrade in absence of oxygen because plastic burns in presence of oxygen. The process is usually conducted in reactor. The gaseous products produced in pyrolysis process are condensed in water cooled condenser to convert to liquid oil.

Pyrolyss is an developing industry to protect the environment and producing the fuel oil to produce alternate fuel oil.

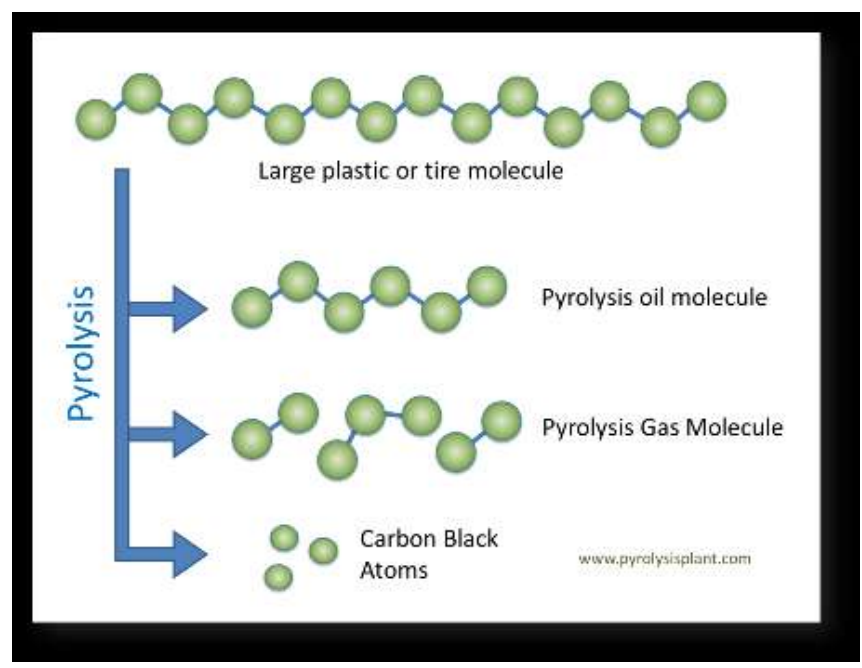




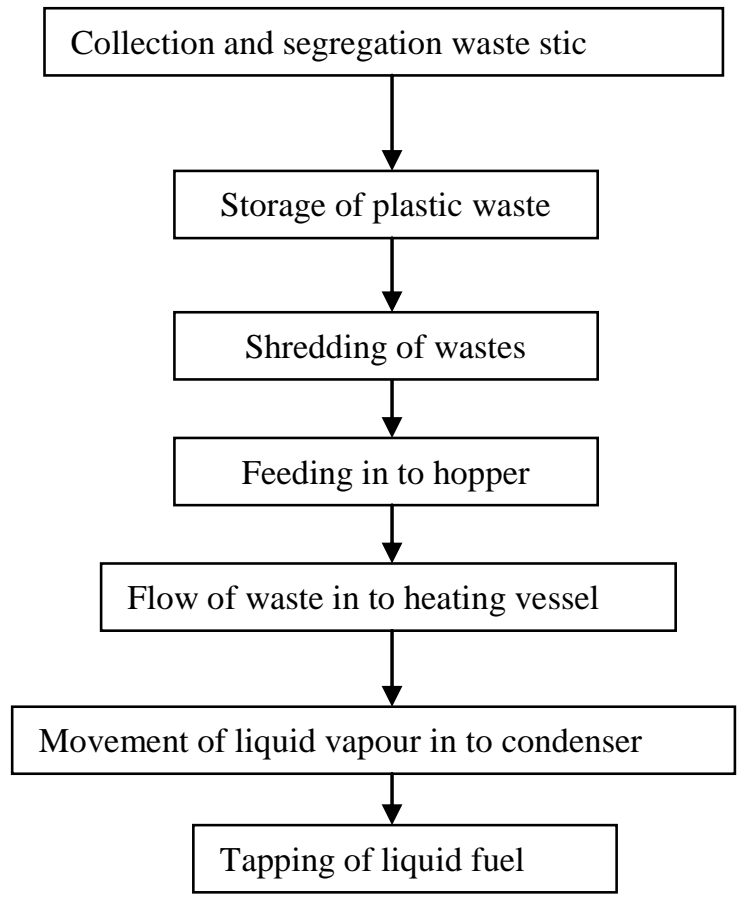

Fig -1: conversion of solid waste in to liquid fuell
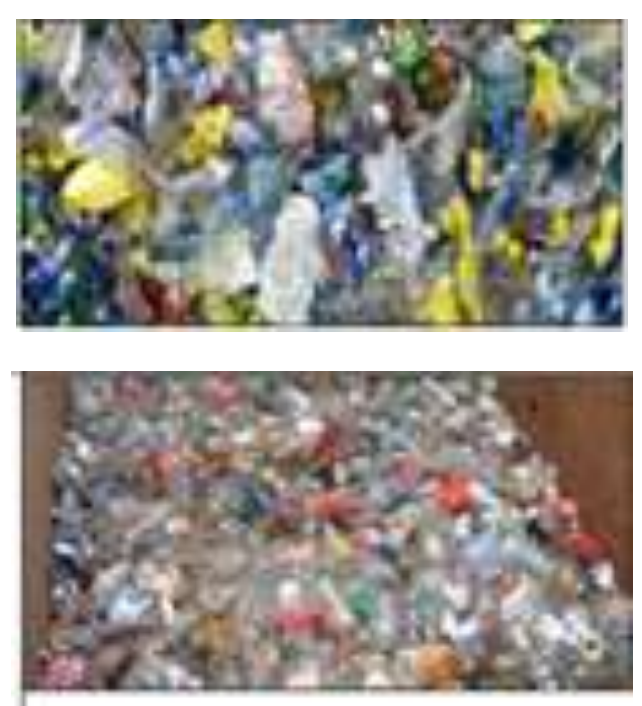

Fig-2: Waste plastics

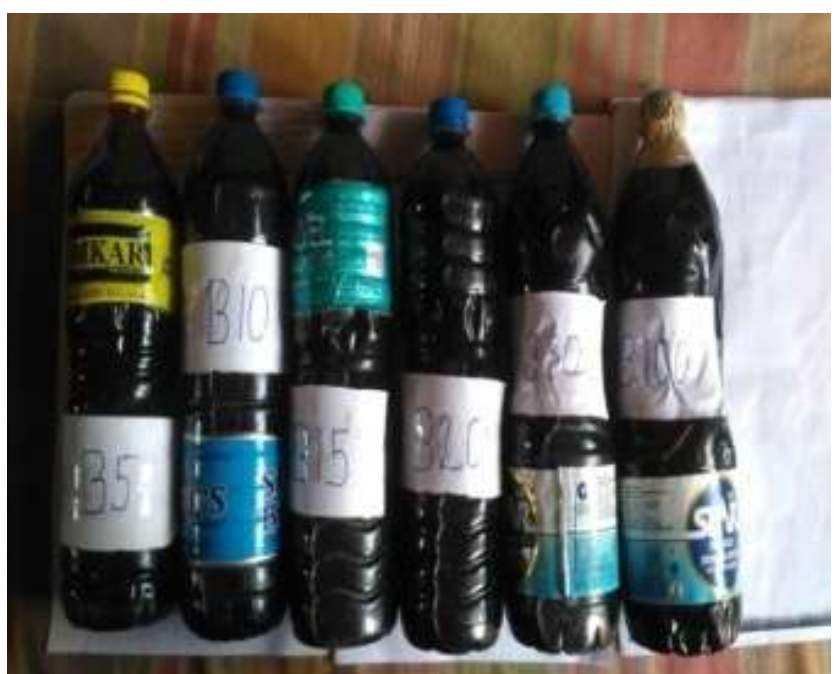

Fig-3: Waste plastic oil

\section{ENGINE SET UP}

The engine used for the test is a single cylinder 4-S diesel engine. The engine produces 5.2 Kilowatt of rate power at $1500 \mathrm{rpm}$ with a compression ratio of $18: 1$. The single cylinder four stroke diesel engine is used for the present work that produces $5.2 \mathrm{KW}$ at $1500 \mathrm{rpm}$.

The Engine Specification is given below in Table:1. The engine test rig is shown in Fig:4 The engine test rig is used for the various tests that are conducted at different load conditions. To start the experiment first engine is started by using diesel oil. This to warm the engine at beginning and then the engine is made to run on different blended oil. Burette is used to record the flow rate and exhaust gas temperature is recorded by sensors.

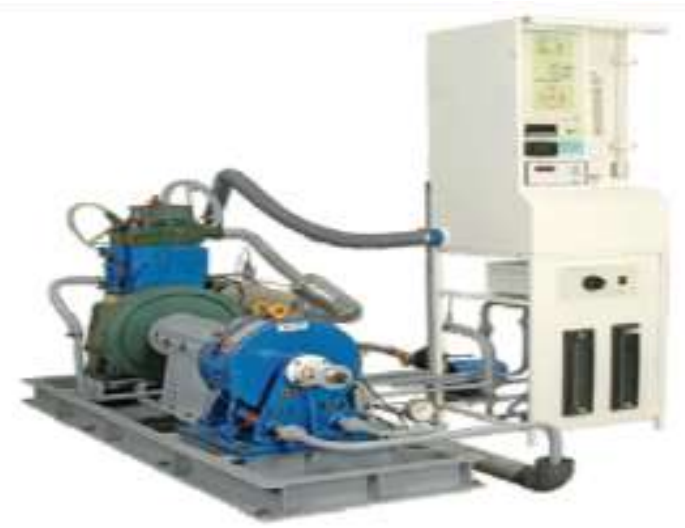

Fig-4: Computerized Single cylinder 4 stroke Diesel engine (VCR engine)

\section{Engine Specifications}

\begin{tabular}{|l|l|l|}
\hline 1 & Parameters & Specifications \\
\hline 2 & Type & TVI (kirlosker made) \\
\hline 3 & Software used & Engine soft. \\
\hline 4 & $\begin{array}{l}\text { Nozzle opening } \\
\text { pressure }\end{array}$ & 200-205 bar \\
\hline 5 & Governor type & Mechanical centrifugal type \\
\hline 6 & No of cylinders & Single cylinder \\
\hline 7 & No of strokes & 4 stroke \\
\hline 8 & Fuel & H.S. diesel \\
\hline 9 & Rated power & 5.2 kw (7hp) at $1500 \mathrm{rpm}$ \\
\hline 10 & $\begin{array}{l}\text { Cylinder diameter } \\
\text { (bore) }\end{array}$ & $87.5 \mathrm{~mm}$ \\
\hline 11 & Stroke length & $110 \mathrm{~mm}$ \\
\hline 12 & Compression ratio & $18: 1$ \\
\hline Air measurement manometer \\
\hline 13 & Made & MX 201 \\
\hline 14 & Type & U type \\
\hline 15 & Range & $100-0-100 \mathrm{~mm}$ \\
\hline Eddy current dynamometer \\
\hline 16 & Model & AG-10 \\
\hline 17 & Type & Eddy current \\
\hline 18 & Maximum & $7.5 \mathrm{Kw}$ at $1500-3000 \mathrm{rpm}$ \\
\hline
\end{tabular}




\section{ENGINE0TESTS}

Engine performance is an indication of the degree of success with which it is doing its assigned job that is the conversion of the chemical energy contained in the fuel into the useful mechanical work. The degree of success is compared on the basis of the following tests.

1. Specific fuel0consumption

2. Break0thermal efficiency

3. Mechanical0Efficiency

4. Volumetric efficiency

5. Exhaust0emissions

Specific1fuel consumption is 2 widely used to 3 compare the performance of different engine. Mean5effective pressure, gives an6indication of engine7displacement utilization8Higher the mean9effective pressure0higher will be2power developed by the3engine for a4given displacement. Brake5thermal efficiency is the6true indication of the efficiency6with which7the thermodynamic3is converted into mechanical work. It also accounts for combustion3efficiency.

\section{PERFORMANCE CHARECTERISTICS OF}

\section{ENGINE}

\subsection{Specific Fuel Consumption}

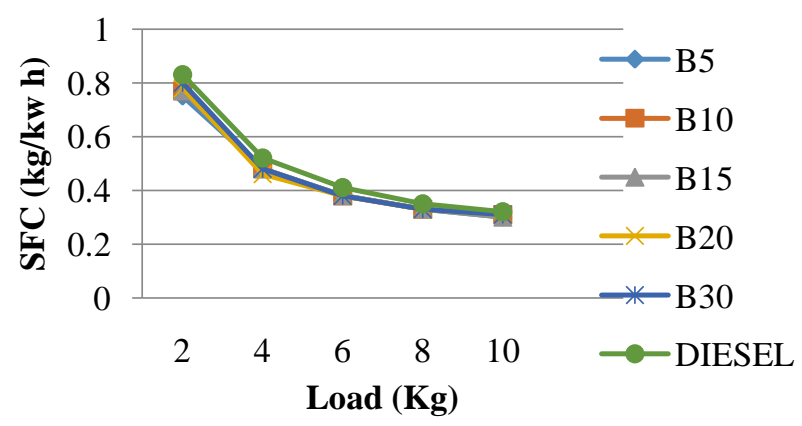

Fig-5: Variation0of Specific0fuel consumption1with Load

Fig-5 shows that variation of specific fuel consumption with load. The graph shows that as the load increases specific fuel consumption decreases. For different blends specific fuel consumption is high in case of diesel.

\subsection{Brake Thermal Efficiency}

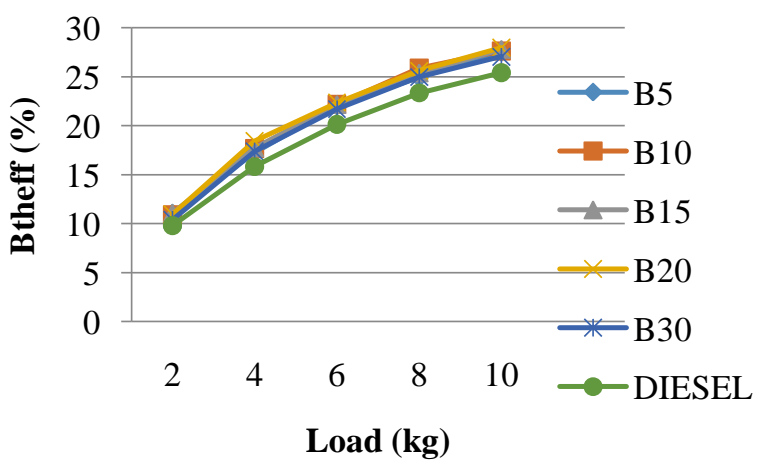

Fig-6: Variation2of BTE with Load

Fig-6 variation of Brake Thermal Efficiency with load.
It is observed that as load increases BTE also increases for different blends. BTE is high in all blends as compared to diesel among all blends. B20 shows higher Brake Thermal Efficiency.

\subsection{Mechanical Efficiency}

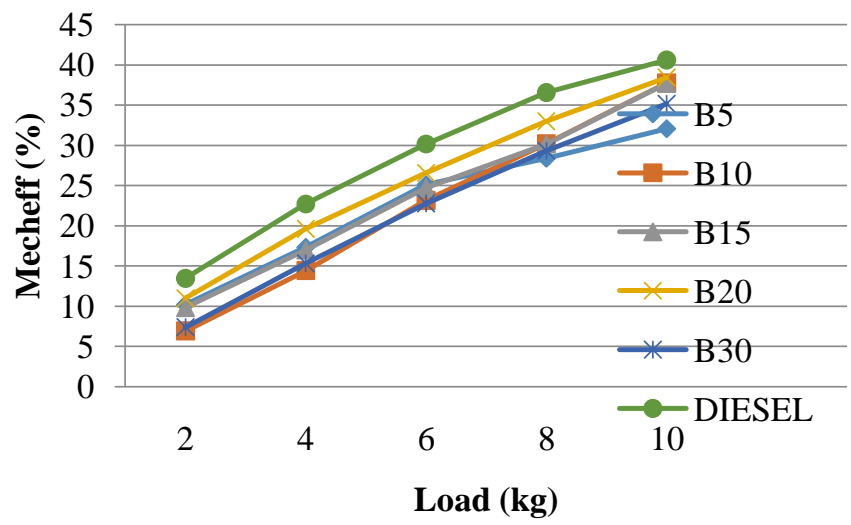

Fig-7: Variation of Mechanical efficiency with Load

Fig-7: Mechanical efficiency variation with load. It is observed that as load increases mechanical efficiency is increases with different blends. Mechanical efficiency is high in case of diesel than all blends.

\subsection{Volumetric Efficiency}

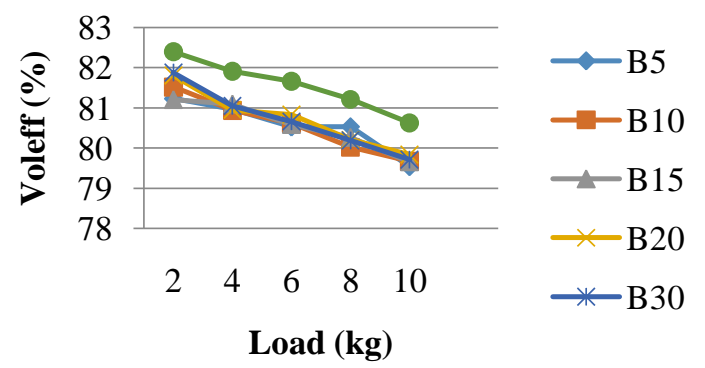

Fig-8: variation of volumetric efficiency with Load

Fig-8:Variation of volumetric efficiency with load. It is observed that the volumetric efficiency is slightly higher than diesel; at full load condition the volumetric efficiency is same in all blends and diesel.

\subsection{Emission Testing}

\subsubsection{Carbon Monoxide}

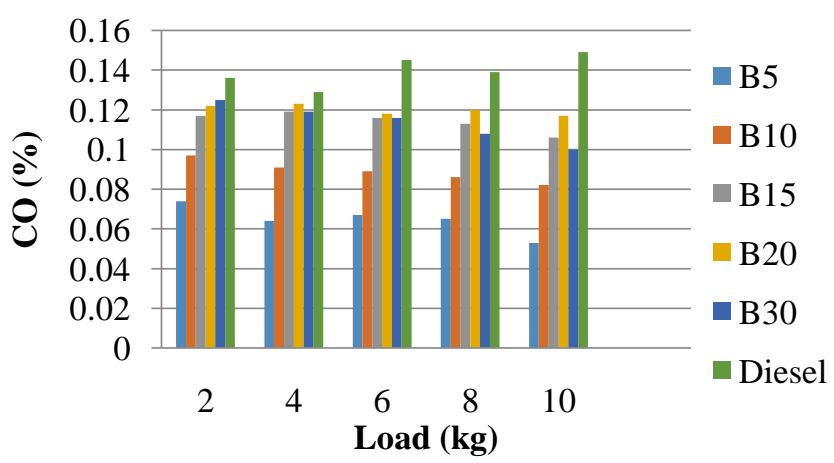

Fig-9: Carbon Monoxide with Load 
Figure: 9.shows that variation of $\mathrm{CO}$ with load. It is observed that as blending increases $\mathrm{CO}$ emission decreses. $\mathrm{CO}$ emission is more in case of diesel as compared to all blends.

\subsubsection{Carbon Dioxide}

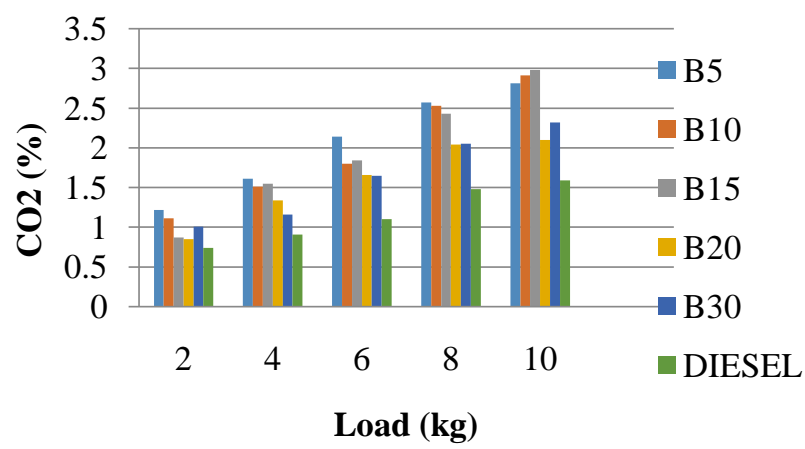

Fig-10: Variation of $\mathrm{CO}_{2}$ with Load

Fig-10: Variation of $\mathrm{CO}_{2}$ with load .It is observed that as load increases the emission of $\mathrm{CO}_{2}$ increases this is because of the more carbon particles in the plastic oil. So the $\mathrm{CO}_{2}$ emission is more as compared to diesel.

\subsubsection{Hydrocarbon}

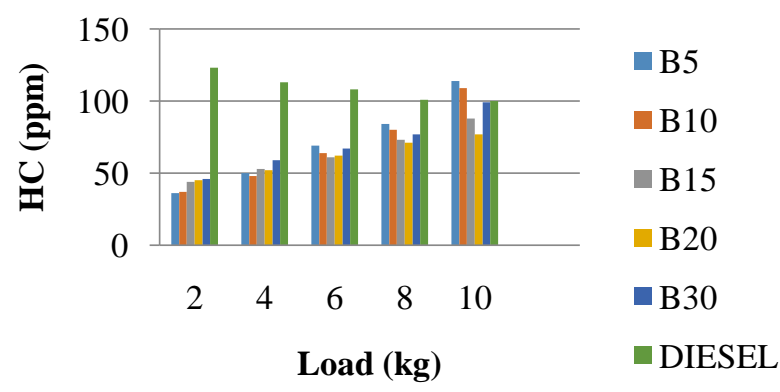

Fig-11: Variation of $\mathrm{HC}$ with Load

Fig-11 shows that variation of HC with load. It is observed that as blending increases the emission of $\mathrm{HC}$ increases, as compared to diesel $\mathrm{HC}$ emission is low in case of blends.

\subsubsection{Nitrogen80xides}

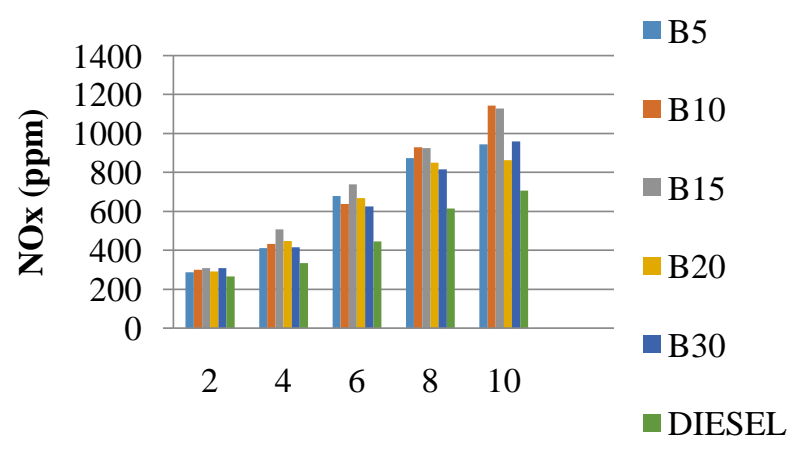

\section{Load (kg)}

Fig-12: Variation6of $\mathrm{NO}_{\mathrm{x}}$ with Load
It is observed that as the blending increases $\mathrm{NO}_{\mathrm{X}}$ emission is goes on increases. $\mathrm{NO}_{\mathrm{X}}$ emissions are higher than diesel this is because of incomplete combustion of oil and higher viscosity of oil.

\section{CONCLUSION}

The following conclusions are made by conducting the experiment using single cylinder engine.

1. The engine can6able to run with $50 \%$ of0blends.

2. After B50 the engine starts to vibrate and emission parameters also increase.

3. From the analysis the blend B20 shows better performance compared to other blends in the sense of better performance characteristics like Brake Thermal Efficiency, specific fuel consumption and decreases in emission like CO, HC. Hence the blend B20 can be used as the substitute for diesel.

4. $\mathrm{NO}_{\mathrm{X}}$ emission is high as compared to diesel.

\section{REFERENCES}

[1]. Achyut K. Panda : "Waste oils as alternative7fuel for diesel engine: A review" :Journal of Petroleum8Technology and Alternative9Fuels,2013

[2]. Pawar Harshal R: "Waste plastic*pyrolysis oil alternative*fuel for CI engines: a review" : Vol 2, Research0journal of Engineering3Sciences, 2013.

[3]. Jane pratoomyod: "Performance and*emission evaluation of 7 blends of diesel fuel with waste 5 plastic oil in a diesel6engine": Vol 2, IJESIT, 2013.

[4]. Anup $\mathbf{T} \mathbf{J}$ [4] studied the1performance, a comparative2study on the3performance, emission and4combustion studies of5a Direct Injection6diesel engine using7distilled waste plastic8pyrolysis oil and9diesel blends. The experimental1results have2showed a stable performance 3 with brake thermal efficiency4similar to that5of diesel. Carbon dioxideland unburned hydrocarbon2were marginally higher4than that of the 5diesel operation. The toxic6gas carbon monoxide1emission of waste5plastic oil was higher2than diesel.

[5]. Mochamad Syamsiro.[5] Analyzed plastic1waste management in2India. There are several3methods for disposal4of municipal and industrial5plastic waste, i.e. landfill, incineration(energy recovery), true material8recycling (similar recycled8product or monomer9recovery), and chemical1recovery. The suitable2treatment of plastic3wastes is one of the 4 key questions of the waste 5 management and is6important from energetic, environmental, economic7and political aspects.

[6].http://environment.about.com/od/earthtalkcolumns/a/rec ycleplastics.htm

[7].http://www.ecomena.org/tag/plastic-waste-disposal/

[8].’Performance Study of aVCR Diesel Engine Fueled With Diesel and Low Concentration Blend of Linseed Oil Biodiesel",Kuldeep Singh1, Mohd. Yunus Sheikh2, Dr.Y. B. Mathur3 www.ijetae.com ISSN 2250-2459, ISO 9001:2008 Certified Journal, Volume 4, Issue 4, April 2014 


\section{BIOGRAPHIES}

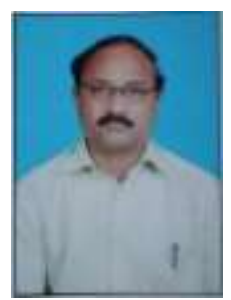

Prof.P.S.Burli has experience of about 15 years in the teaching field. Worked as shift engineer in sugar industry for 4 years. Passed Boiler operative Engineer conducted by Govt of Karnataka. 